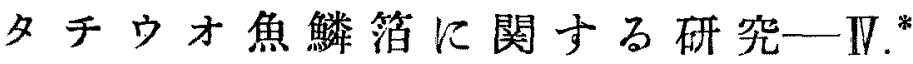 精製䈃中の殘留脂質につけて
}

\author{
太田冬雄 \\ (鹿児息大学水産学部)
}

\section{Chemical Studies on Lustrous Particles in Epidermis of Hair-tail, Trichiurus haumela-IV.}

On the Lipids Remaining in Its Refined Particles

Fuyuo OtA

In the previous paper, it was infered that lipids, especially phosphatides-like matter, in the lustrous particles will be hard to te removed in the process of refining raw particles to make the pearl essence. In this study, the composition of lipids in the considerably refined particles, was compared with that of raw particles. The results obtained were as follows:

1) In the refined particles, about $28 \%$ of lipids contained in the raw particles was still remained.

2) The rate of both oil and unsaponifiable matter in lipids noticezbly decreased, but, on the contrary, that of acetone insoluble matter increased in the refined particles.

From the above mentioned results, it was ascertained that phosphatides or its resembling matters in raw particles were harder to be removed than fatty oil and unsaponifiable matter in the refining prccess.

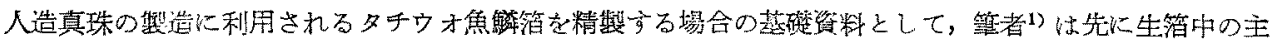

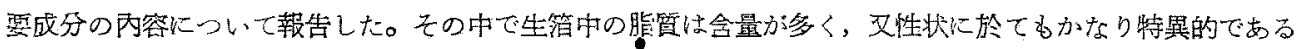

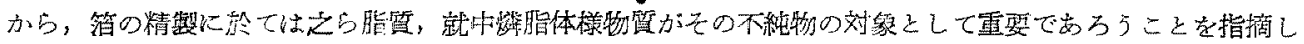

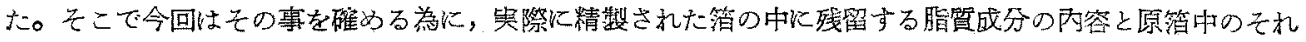

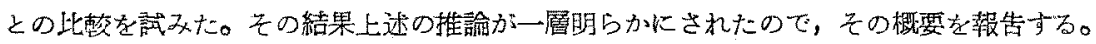

$$
\text { 䒠 駰 }
$$

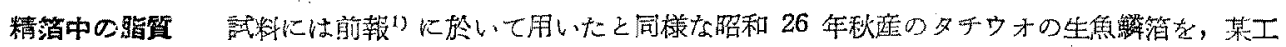

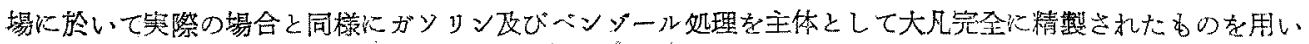

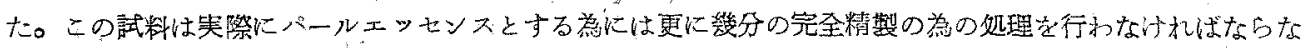

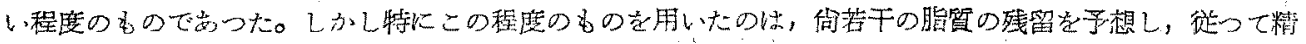
整過程にある箈中の脂望成分の內容の変化を知る為の好試料と若えたからである。

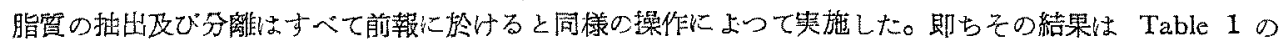

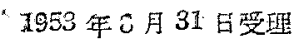




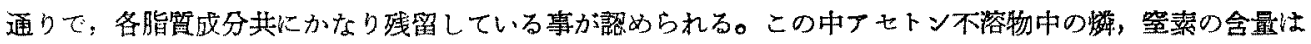
前報に示したと同様の方法に上つて定量した結果，夫及橉（P) は 1.88，尊素 (N) は 1.78\% であつた。

Table 1. Moisture and lipids contents of refined particles.

\begin{tabular}{c|c|c|c|c}
\hline $\begin{array}{c}\text { Moisture } \\
\%\end{array}$ & $\begin{array}{c}\text { Lipid } \\
\%\end{array}$ & $\begin{array}{c}\text { Oil } \\
\%\end{array}$ & Acetone insoluble & \multicolumn{2}{|c}{ Unsaponifiable } \\
matter $\%$
\end{tabular}

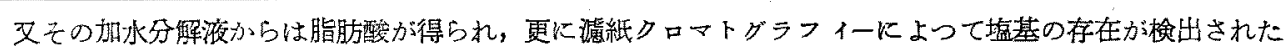

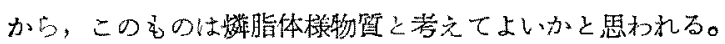

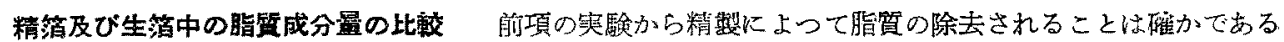

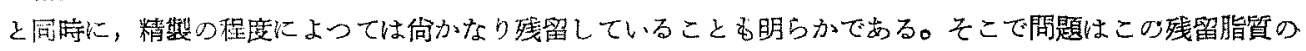

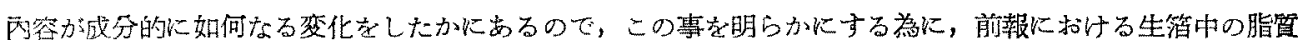
の成分上の関保を比較した。

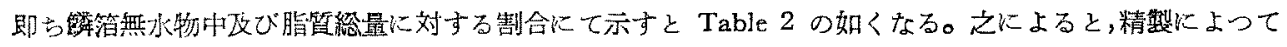
約 $72 \%$ の脂質か除去されているが，佾䄪 $25 \%$ が残留する。而も之を成分的に見ると，脂油は約 $23 \%$ ，不 化物は約 $11 \%$ に隇じているに抱らず，アャトン不溶物は殆ど大部分の約 $82 \%$ が残留し，他に比し除去 され難からた事か政められる。この事は両試料中のアセトン不溶物に対する脂油の比率の上から見ると更に 明らかである。

Table 2. Comparative composition of lipids of refined and raw particles.

\begin{tabular}{|c|c|c|c|c|c|c|c|c|}
\hline & \multirow{2}{*}{$\begin{array}{c}\% \\
\text { Lipids } \\
\text { moist. } \\
\text { free basis }\end{array}$} & \multicolumn{2}{|c|}{$\begin{array}{c}\mathrm{Oil} \\
\% \\
\end{array}$} & \multicolumn{2}{|c|}{$\begin{array}{c}\text { Unsaponifiable matter } \\
\%\end{array}$} & \multicolumn{2}{|c|}{$\begin{array}{c}\text { Acetone insoluble } \\
\text { matter } \%\end{array}$} & \multirow{2}{*}{$\begin{array}{l}\text { Acetone } \\
\text { insoluble } \\
\text { matter } \\
\text { /oil }\end{array}$} \\
\hline & & $\begin{array}{l}\text { moist. } \\
\text { free basis }\end{array}$ & lipids & $\begin{array}{l}\text { moist } \\
\text { free basis }\end{array}$ & lipids & $\begin{array}{l}\text { moist. } \\
\text { free basis }\end{array}$ & lipids & \\
\hline $\begin{array}{l}\text { Refined } \\
\text { Particles }\end{array}$ & 10.12 & 7.45 & 73.33 & 0.75 & 7.51 & 2.67 & 26.67 & 0.35 \\
\hline $\begin{array}{l}\text { Raw } \\
\text { Particles }\end{array}$ & 36.37 & 33.09 & 90.99 & 7.02 & 19.34 & 3.24 & 8.95 & 0.09 \\
\hline $\begin{array}{l}\text { Amt. in re- } \\
\text { fined part. } \\
\text { /Amt. in } \\
\text { raw part. }\end{array}$ & 0.277 & 0.225 & - & $q .106$ & - & 0.824 & - & - \\
\hline
\end{tabular}

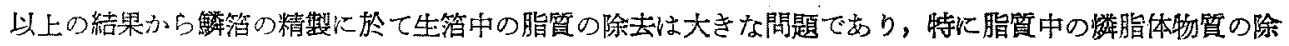

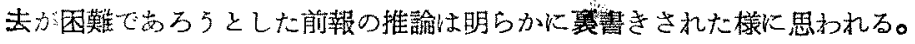

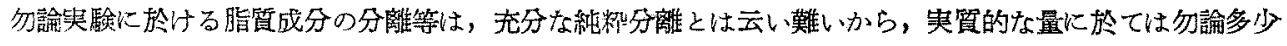

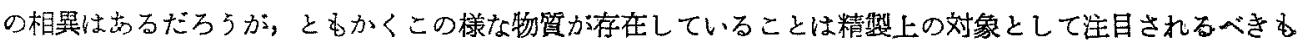
のと考兄られる。

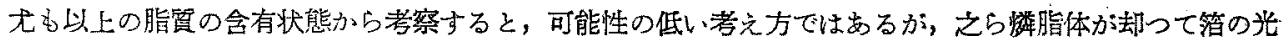
沢に対する下地として徍立つのではないかと云う見方るある様に思われるので，この点は今後実際の製品に ついて㫛算との関倸を追究して明らかにしたいと思ら。

総括

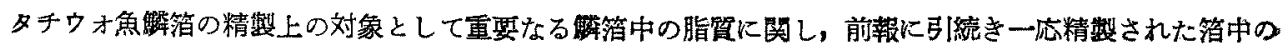


成芀內溶を㛟索し，之を生䇴中のそれに比较した。

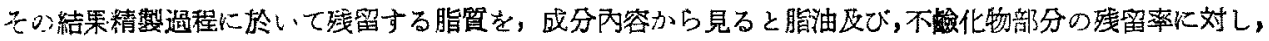

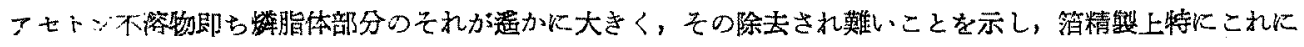

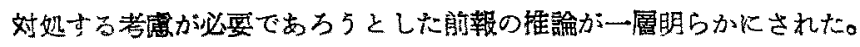

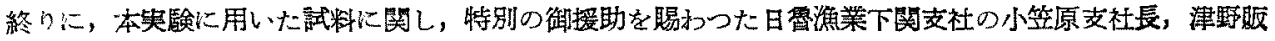
夲課長及び吉松英一の諸氏に感謝の意を表する。

捎本報の概要は，日本水库学会大会（拎東京，昭 27.4）飞て講演した。

女 觔

1）太田 冬雄：本誌，19，1123 1126 (1954). 